Научная статья

УДК 37.014

DOI: 10.18101/2307-3330-2021-2-28-39

\title{
БЛАГОПОЛУЧИЕ ДЕТЕЙ: СТРАТЕГИЯ И ПРАКТИКА СОПРОВОЖДЕНИЯ СЕМЕЙ С ДЕТЬМИ, ИМЕЮЩИМИ ПСИХОЛОГО-ПЕДАГОГИЧЕСКИЕ ПРОБЛЕМЫ
}

\author{
(c) Ванданова Эльвира Леонидовна \\ кандидат психологических наук, доцент, \\ Российская академия народного хозяйства и государственной службы \\ при Президенте РФ \\ Россия, 119571, г. Москва, ул. Вернадского, 82 \\ vandanova-el@ranepa.ru
}

Аннотация. В статье анализируются вопросы благополучия детей и сопровождения в образовательных организациях семей с детьми, имеющими психологопедагогические проблемы. Защита прав детей и психологическая безопасность детей и взрослых — важная проблематика для России из-за ухудшения демографической ситуации и рисков вовлечения молодежи в преступную и другую деструктивную деятельность. В ходе работы: 1) проанализирован ряд исследований психологического благополучия детей и подростков в современном образовательном пространстве, отмечается множественный подход к благополучию детей, в данной статье акцентируются вопросы - семья и благополучие детей, экологический подход к благополучию детей, реализация права ребенка на благополучие; 2) проанализированы отечественные Федеральные государственные образовательные стандарты (далее - ФГОС) второго и третьего поколения, выявлены условия реализации права ребенка на благополучие в соответствии с российским законом об образовании и ФГОСами, таким условием выступает организация психологопедагогического сопровождения всех участников образовательного процесса; 3) представлены разработанные методические рекомендации для представителей органов управления образованием субъектов Российской Федерации по организации психолого-педагогического сопровождения семей, воспитывающих детей и подростков, имеющих психолого-педагогические проблемы.

Ключевые слова: благополучие ребенка, семья, социализация, государственная политика в сфере образования, психолого-педагогические проблемы детей.

Благодарности. Работа выполнена в рамках научно-исследовательской работы Федерального института развития образования РАНХиГС.

\section{Для цитирования}

Ванданова Э. Л. Благополучие детей: стратегия и практика сопровождения семей с детьми, имеющими психолого-педагогические проблемы // Вестник Бурятского государственного университета. Образование. Личность. Общество. 2021. № 2. С. 28-39.

Введение. Благополучие детей - это сложная концепция, не имеющая общепринятого измерения, один общий подход к концептуализации благополучия детей состоит в том, чтобы рассматривать его как многомерную концепцию, охватывающую ментальные/психологические, социальные и физические аспек- 
Э. Л. Ванданова. Благополучие детей: стратегия и практика сопровождения семей с детьми, имеющими психолого-педагогические проблемы

ты ${ }^{1}$. Необходимо провести различие между «психологическим благополучием», которое касается оценки различных психологических состояний человека, и «субъективным благополучием», которое включает субъективную оценку человеком любого аспекта своей жизни (например, финансов, физического здоровья). Хотя эти два термина часто используются как синонимы, ни одна из этих категорий не включает в себя другую. Далее, вслед за Чэпли и Ричардсоном мы будем использовать «психологическое благополучие» или «субъективное благополучие» в их более общем описательном смысле, а не для обозначения каких-либо конкретных показателей.

Методы. Выбранная исследовательская методология - это сочетание системно-деятельностного, аксиологического, антропологического, личностноориентированного и компетентностных подходов.

Целью работы является анализ исследований психологического благополучия детей и подростков в современном образовательном пространстве.

Задачи: изучить теории социализации и благополучия детей, модели сопровождения семей с детьми, имеющими психологические проблемы; разработать методические рекомендации для представителей органов управления образованием субъектов Российской Федерации по организации психологопедагогического сопровождения семей, воспитывающих детей и подростков, имеющих психолого-педагогические проблемы.

Результаты. Несмотря на измерительные и концептуальные проблемы, недавнее распространение исследований благополучия позволило получить множество интересных результатов и новых идей [2]. Благополучие детей считается прикладной темой, поэтому публикации по этой теме можно найти в основном в научной литературе по прикладной социальной психологии, психосоциальной интервенции, в междисциплинарных журналах по социальной политике, проблем семьи, детства и юношества [5].

Обзор вклада, внесенного в разработку концепции благополучия детей, будет неполным, если в нем не будет работ позитивной психологии. Как и в случае с большинством гуманитарных и социальных наук, большая часть исследований благополучия исторически проводилась с опорой на негативные аспекты (недостаток или отсутствие благополучия): социальные психологи сосредоточились в основном на социальных проблемах детей. За последние 20 лет эта тема рассматривается в фундаментальной и прикладной психологии с позитивной точки зрения у Селигмана и Динера, в позитивной психологии М. Чиксентмихайи [4], Б. Фредриксон [6], И. Бонивелл [1], Д. А. Леонтьева [3].

В числе исследований в рамках позитивной психологии работа «Психология детского благополучия», авторы - А. Хольте, М. Барри, М. Бекхус, Э. Ингер, Х. Борге, Л. Боуз, Ф. Касас и другие ${ }^{2}$. Благополучие детей рассматривается с

\footnotetext{
${ }^{1}$ Об утверждении Положения о психолого-медико-педагогической комиссии: приказ Минобрнауки России от 20.09.2013 г. № 1082. URL: https://www.mos.ru/ upload/documents/oiv/pr_mo_1082_20_08_2013_r13.pdf (дата обращения: 20.02.2021). Текст: электронный.

${ }^{2}$ Psychology of Child Well-Being // A. Ben-Arieh, F. Casas, I. Frønes, J. Korbin (eds). Handbook of Child Well-Being. Springer, Dordrecht. Holte A. et al. (2014). URL: https://doi.org/10.1007/978-90-481-9063-8_13 (дата обращения: 20.02.2021).
} 
психологической точки зрения и охватывает широкий спектр психологических дисциплин - от эволюционной психологии и генетики поведения через психометрию до психологии развития, когнитивной, личностной и социальной психологии.

Значимые исследования благополучия детей представлены в монографии «Справочник по благополучию детей: теории, методы и политика в глобальной перспективе» под редакцией А. Бен-Арье, Ф. Касаса, И. Фронеса, Д. Э. Корбин. В аннотации к изданию авторы дают следующую информацию: «<..> Благополучие детей представляет собой проблему, которая еще не решена, и «Справочник благополучия детей» предлагает своим читателям подробный обзор сложностей и последствий, связанных с научным и практическим стремлением к благополучию детей $<\ldots>$ рассматривается концепция благополучия на основе анализа точек зрения различных дисциплин, таких как философия, теология, психология и социология. $<\ldots>$ материал охватывает важные вопросы благополучия детей и проблемы общей политики благополучия, а также реализацию интервенционных программ и мер $<\ldots>$ рассматриваются методы измерения благополучия для получения научно обоснованного понимания, а также для разработки политики» ${ }^{1}$. Описанный справочник содержит 4 тома, в которые входят разделы и 87 глав. В каждой главе описываются самостоятельные исследования и подходы. За отправную точку берется идея - благополучие детей лучше всего понимать в рамках многокультурного и многодисциплинарного подхода, охватывающего широкий спектр подходов и контекстов. Авторы представили различные взгляды на благополучие детей и подростков в разных обществах, нациях и культурах. По мнению Томаса С. Вайснера, существуют концепции счастья и целей жизни в разных сообществах по всему миру [8]. Х. Б. Нильсен отмечает: «Опыт детей Севера и Юга сходится в динамике глобального капитализма с высокими темпами миграции и распространением коммерциализированной культуры и товаров, предназначенных для детей» [7]. В последние годы, как отмечает Дж. Х. МакКендрик, возрастает интерес к макрогеографии благополучия детей. Это зависит от того, где они живут.

Для выявления условий реализации права ребенка на благополучие в Российской Федерации были рассмотрены Федеральные государственные стандарты разных поколений. При сравнении ФГОС 2010 и 2021 гг. следует обратить внимание на обозначенные психолого-педагогические условия реализации ООП ООО. Во ФГОС 2010 г. в пункте 26 указываются преемственность, вариативность ${ }^{2}$. Все условия отображены на рисунке 1.

\footnotetext{
${ }^{1}$ Ben-Arieh A., Frones I., Casas F., Korbin J. E. (Ed.). Handbook of Child Well-Being. Theories, Methods and Policies in Global Perspective (2093-2133). Dordrecht: Springer, 2014.

${ }^{2}$ Об утверждении Положения о психолого-медико-педагогической комиссии: приказ Минобрнауки России от 20.09.2013 г. № 1082. URL: https://www.mos.ru/upload/ documents/oiv/pr_mo_1082_20_08_2013_r13.pdf (дата обращения: 12.09.2021). Текст: электронный.
} 
Э. Л. Ванданова. Благополучие детей: стратегия и практика сопровождения семей с детьми, имеющими психолого-педагогические проблемы

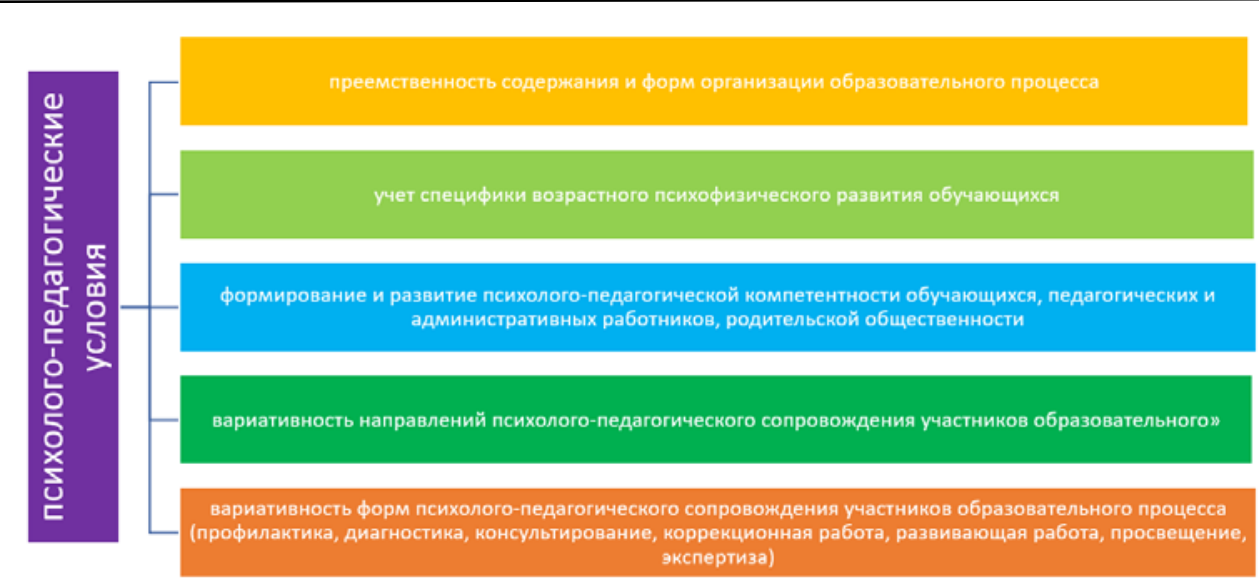

Рис. 1. Перечень психолого-педагогических условий

ФГОС основного общего образования нового образца от 2021 г. $^{1}$, в пункте 38 документа, психолого-педагогические условия реализации программ ООО включают в себя содержание, уровни, формы психолого-педагогического сопровождения (рис. 2).

Анализ психолого-педагогических условий реализации программ показал, что сохранилась преемственность содержания и форм, вариативность, вместе с тем более половины обозначенных условий (5 условий из 9) описывают психолого-педагогическое сопровождение, обучающихся, родителей и всех участников образовательного процесса (рис. 2).

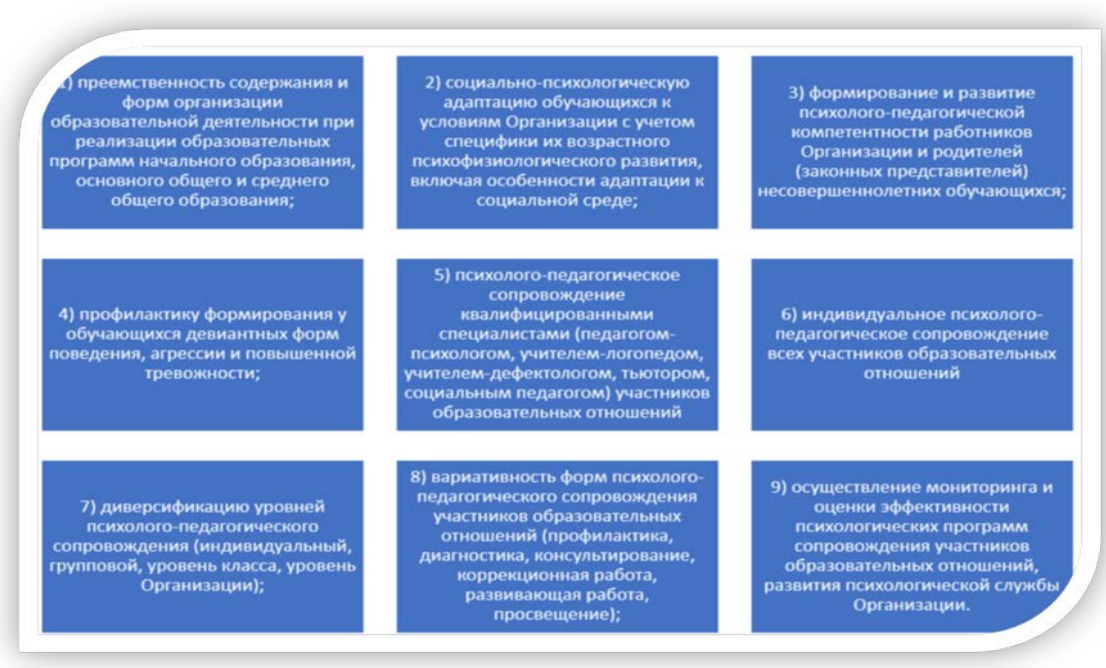

Рис. 2. Психолого-педагогические условия реализации программы основного общего образования (п. 38 ФГОС 2021 г.)

${ }^{1} \mathrm{O}$ сопровождении образования обучающихся с ОВЗ и инвалидностью: письмо Минпросвещения России от 20.02.2019 г. № TC-551/07 (разъяснения о должностях «тьютор» и «ассистент (помощник)»). URL: https://rulaws.ru/acts/Pismo-MinprosvescheniyaRossii-ot-20.02.2019-N-TS-551_07 (дата обращения: 20.02.2021). Текст: электронный. 
Определены квалифицированные специалисты, осуществляющие сопровождение: педагог-психолог, логопед, дефектолог, тьютор и социальный психолог, а также все участники сопровождения (блок 5 на рис. 2).

Определена диверсификация уровней и форм:

- 5 уровней психолого-педагогического сопровождения, начиная с индивидуального и до уровня организации (блок 7 на рис. 2);

- 6 форм психолого-педагогического сопровождения: профилактика, диагностика, консультирование, коррекционная работа, развивающая работа, просвещение (блок 8 на рис. 2).

В числе субъектов сопровождения значатся родители и законные представители учащихся (рис. 3).

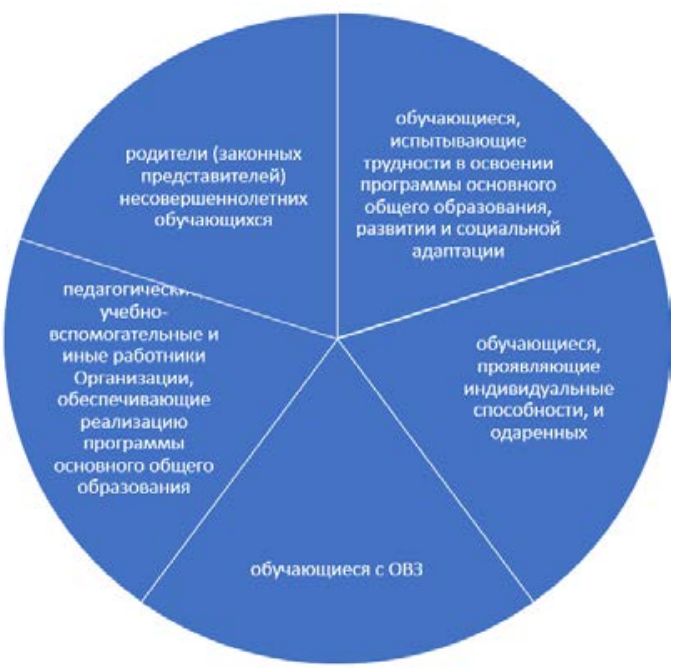

Рис. 3. Индивидуальное психолого-педагогическое сопровождение всех участников

Обсуждение. Благополучие - это активное участие в деятельности, которая считается желательной и ценной в культурном сообществе, а также психологический опыт, который возникает в результате такого участия. Смешанные качественные и количественные методы, включая полевую этнографию и разговорные интервью, являются важными методами культурного понимания благополучия ${ }^{1}$. Подчеркивая гендерные, образовательные, социальные, экологические модели в детской работе, учебе и отношениях со сверстниками, исследователи в первую очередь ориентируются на оценку жизни и благополучия детей и подростков в экономически развитых странах [8].

${ }^{1}$ Об утверждении порядка организации и осуществления образовательной деятельности по основным общеобразовательным программам - образовательным программам начального общего, основного общего и среднего общего образования: приказ Министерство образования и науки Российской Федерации от 30 августа 2013 г. № 1015. URL: https://rg.ru/2013/10/16/obrprogrammy-dok.html (дата обращения: 12.09.2021). Текст: электронный. 
Э. Л. Ванданова. Благополучие детей: стратегия и практика сопровождения семей с детьми, имеющими психолого-педагогические проблемы

Особое внимание уделяется факторам формирования благополучия: месту проживания, среде обучения и другим условиям социализации. Для благополучия детей «хорошие места» ${ }^{1}$ :

1) инклюзивны, позволяют иметь всем детям одинаковый опыт;

2) динамичны, предоставляют детям возможность проявлять активность;

3) просторны, обладают соответствующими пространством и помещениями;

4) гарантированы, обеспечены ресурсами с ключевыми услугами.

Все вышеуказанные характеристики «хороших мест» описывают экологические среды развития и социализации ребенка согласно теории Брофенбреннера. В связи с этим организация психолого-педагогического сопровождения семей с детьми приобретает отдельную значимость.

Нами выделена примерная модель психолого-педагогического сопровождения семей, воспитывающих детей и подростков, имеющих психологопедагогические проблемы. Примерная модель основана на ФГОС нового образца от 2021 г.

Для модели необходимо определение категорий детей и подростков, имеющих психолого-педагогические проблемы. Законодательно закрепленного определения данной категории детей не существует. Вместе с тем, согласно новому ФГОС, выделяется три группы обучающихся:

- дети и подростки с ОВ3,

- дети и подростки, имеющие способности и одаренные,

- испытывающие трудности в обучении и адаптации.

Отдельно указывается на необходимость профилактики девиаций, агрессии и тревожности. В целях указанной профилактики необходимо руководствоваться принципами межведомственного взаимодействия. Основание межведомственного взаимодействия разрабатывается для реализации положений п. 1 и 2 ч. 1 ст. 11 Федерального закона от 24.06.1999 г. № 120-Ф3 «Об основах системы профилактики безнадзорности и правонарушений несовершеннолетних» для осуществления мер по защите и восстановлению прав и законных интересов несовершеннолетних, выявлению и устранению причин и условий, способствующих безнадзорности, беспризорности, правонарушениям и антиобщественным действиям несовершеннолетних, координации вопросов, связанных с соблюдением условий их воспитания, обучения и содержания, организации работы по раннему выявлению семейного неблагополучия» ${ }^{2}$. Содержание сопровождения определяется 10 направлениями деятельности (рис. 4).

${ }^{1} \mathrm{O}$ сопровождении образования обучающихся с ОВ3 и инвалидностью: письмо Минпросвещения России от 20.02.2019 г. № ТС-551/07 (разъяснения о должностях «тьютор» и «ассистент (помощник)»). URL: https://rulaws.ru/acts/Pismo-MinprosvescheniyaRossii-ot-20.02.2019-N-TS-55107 (дата обращения: 20.02.2021). Текст: электронный.

2 Об утверждении Федерального государственного образовательного стандарта среднего (полного) общего образования: приказ Министерства образования и науки Российской Федерации (Минобрнауки России) от 17 мая 2012 г. № 413 г. URL: https://rg.ru/2012/06/21/obrstandart-dok.html (дата обращения: 20.02.2021). Текст: электронный. 


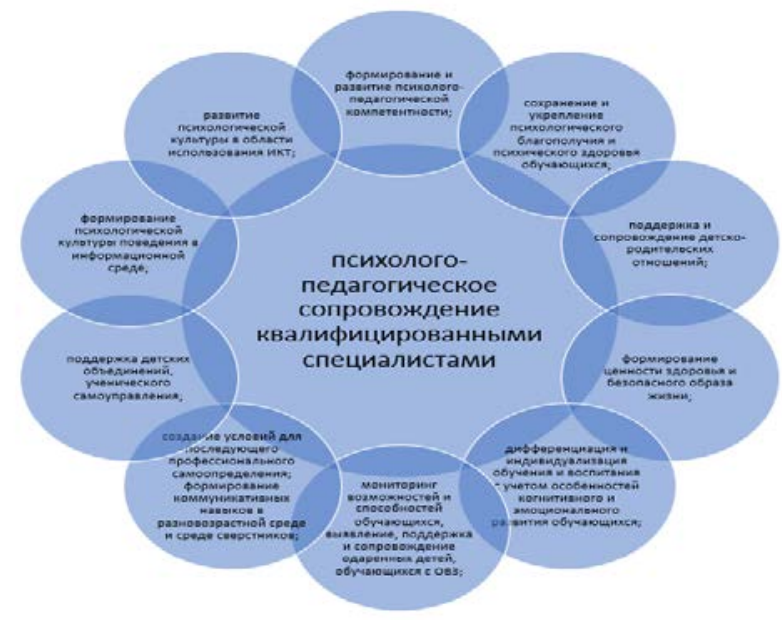

Рис. 4. Содержание психолого-педагогического сопровождения

Приведем определение категорий семей для организации психологопедагогического сопровождения семей, воспитывающих детей и подростков, имеющих психолого-педагогические проблемы:

- организация работы с семьями, воспитывающими детей и подростков, проявляющих девиантные формы поведения, агрессии и повышенной тревожности.

- с семьями, имеющими детей и подростков с ОВ3 и инклюзивное образование.

- одаренными детьми и подростками.

- семьями, находящимися в социально опасном положении (трудной жизненной ситуации).

В дополнение к определению содержания психолого-педагогического сопровождения обучающихся и их семей обратимся к должностным обязанностям тьютора, в которые входит «педагогическое сопровождение реализации индивидуальных образовательных маршрутов обучающихся» (п. 1), что определяется в письме Минпросвещения: «оказание помощи семье в построении семейной образовательной среды для поддержки обучающихся в освоении индивидуальных учебных планов и адаптированных образовательных программ» ${ }^{1}$.

В целях оказания помощи органам управления образованием субъектов РФ были разработаны методические рекомендации по организации психологопедагогического сопровождения детей и подростков, имеющих психолого-

\footnotetext{
${ }^{1}$ Профессиональный стандарт «Педагог-психолог» (психолог в сфере образования), утвержден приказом Министерства труда и социальной защиты Российской Федерации от 24 июля 2015 г. № 514н. URL: https://profstandart.rosmintrud.ru/obshchiyinformatsionnyy-blok/natsionalnyy-reestr-professionalnykh-standartov/reestr-professionalnykhstandartov/index.php? ELEMENT_ID=57963. Текст: электронный.
} 
Э. Л. Ванданова. Благополучие детей: стратегия и практика сопровождения семей с детьми, имеющими психолого-педагогические проблемы

педагогические проблемы, в соответствии с законом об образовании ${ }^{1}$, ФГОС $^{2}$, 442-Ф3, 120-Ф3, 124-Ф3 ${ }^{3}$, Семейным кодексом ${ }^{4}$. Другие нормативно-правовые акты, регулирующие психолого-педагогическое сопровождение семей, имеющих детей с психолого-педагогическими проблемами: профстандарт педагогапсихолога ${ }^{5}$, приказы и письма профильного ведомства ${ }^{6}$.

${ }^{1}$ Об образовании в Российской Федерации: федер. закон от 29.12.2012 г. № 273-Ф3. Текст: непосредственный.

${ }^{2}$ Об утверждении Положения о психолого-медико-педагогической комиссии: приказ Минобрнауки России от 20.09.2013 г. № 1082. URL: https://www.mos.ru/upload/ documents/oiv/pr_mo_1082_20_08_2013_r13.pdf (дата обращения: 20.02.2021). Текст: электронный;

О сопровождении образования обучающихся с ОВ3 и инвалидностью: письмо Минпросвещения России от 20.02.2019 г. № ТС-551/07 (разъяснения о должностях «тьютор» и «ассистент (помощник)»). URL: https://rulaws.ru/acts/Pismo-MinprosvescheniyaRossii-ot-20.02.2019-N-TS-55107 (дата обращения: 20.02.2021). Текст: электронный.

${ }^{3}$ О направлении информации: письмо Минпросвещения России от 16.05.2019 г. № TC-1192/03 (по вопросу обучения в группах компенсирующей и комбинированной направленности детей разных категорий). URL: http://www.garant.ru/products/ ipo/prime/doc/72159890/?prime (дата обращения: 12.09.2021). Текст: электронный;

О сопровождении образования обучающихся с ОВ3 и инвалидностью: письмо Минпросвещения России от 20.02.2019 г. № TC-551/07 (разъяснения о должностях «тьютор» и «ассистент (помощник)»). URL: https://rulaws.ru/acts/Pismo-MinprosvescheniyaRossii-ot-20.02.2019-N-TS-551_07 (дата обращения: 12.09.2021). Текст: электронный;

Об утверждении Федерального государственного образовательного стандарта среднего (полного) общего образования: приказ Министерства образования и науки Российской Федерации (Минобрнауки России) от 17 мая 2012 г. № 413 г. Москва. URL: https://rg.ru/2012/06/21/obrstandart-dok.html (дата обращения: 12.09.2021). Текст: электронный.

${ }^{4}$ Об основах социального обслуживания граждан в Российской Федерации: федер. закон от 28.12.2013 г. № 442-Ф3 (последняя редакция). URL: http://www. consultant.ru/document/cons_doc_LAW_156558/ (дата обращения: 12.09.2021). Текст: электронный.

${ }^{5}$ Об основах системы профилактики безнадзорности и правонарушений несовершеннолетних: федер. закон от 24.06.1999 г. № 120-Ф3 (последняя редакция). Текст: непосредственный.

${ }^{6}$ Об основных гарантиях прав ребенка в Российской Федерации: федер. закон от 24.07.1998 г. № 124-Ф3. Текст: непосредственный;

Семейный кодекс Российской Федерации от 29.12.1995 г. № 223-Ф3 (ред. от 04.02.2021, с изм. от 02.03.2021). Текст: непосредственный;

Профессиональный стандарт «Педагог-психолог» (психолог в сфере образования), утвержден приказом Министерства труда и социальной защиты Российской Федерации от 24 июля 2015 г. № 514н. URL: https://profstandart.rosmintrud.ru/obshchiyinformatsionnyy-blok/natsionalnyy-reestr-professionalnykh-standartov/reestr-professionalnykhstandartov/index.php?ELEMENT_ID=57963 (дата обращения: 20.02.2021). Текст: электронный;

Об утверждении порядка организации и осуществления образовательной деятельности по основным общеобразовательным программам - образовательным программам начального общего, основного общего и среднего общего образования: приказ Министерство образования и науки Российской Федерации от 30 августа 2013 г. № 1015. URL: 
В указанные методические рекомендации были включены примерная модель психолого-педагогического сопровождения семей, воспитывающих детей и подростков, имеющих психолого-педагогические проблемы, и Алгоритм действий общеобразовательных организаций по психологопедагогическому сопровождению семей, воспитывающих детей и подростков, имеющих психолого-педагогические проблемы, содержит алгоритм сопровождения и перечень ответственных за формы сопровождения:

- выявление семей, воспитывающих детей и подростков, имеющих психолого-педагогические проблемы, на основе обращения родителей, а также на основе межведомственного взаимодействия с комиссией по делам несовершеннолетних, территориальных служб, социальными служб, медицинскими учреждениями, организациями, осуществляющими психологопедагогическую помощь в работе детьми и подростками (руководитель образовательной организации или его заместитель, социальный педагог образовательной организации).

- диагностика развития детей и подростков, имеющих психологопедагогические проблемы, с помощью инструментария для проведения опроса с целью выявления у детей и подростков личностной устойчивости к конфликтам, особенностей семейного воспитания (педагог-психолог образовательной организации), профилактики социально опасного поведения, в том числе в социальных сетях;

- ознакомление родителей с результатами психолого-педагогической диагностики до участия в психолого-педагогических программах (реализует педагог-психолог совместно с социальным педагогом образовательной организации);

- организация и оценка родителями благополучия ребенка в школьной среде с помощью анкеты «Школьная жизнь моего ребенка» (педагог-психолог образовательной организации);

- разработка индивидуальных учебных планов и адаптированных образовательных программ и ознакомление родителей с документами с целью получения их согласия для дальнейшей работы с ребенком по указанным планам и программам (тьютор, учитель-дефектолог образовательной организации);

- организация и проведение с семьями обучающихся работы по программам социализации детей и подростков в современном информационном обществе (педагог-психолог образовательной организации);

- отслеживание динамики развития детей и подростков, имеющих психолого-педагогические проблемы, и информирование родителей о результатах (реализует педагог-психолог совместно с социальным педагогом образовательной организации);

- профилактика девиаций, агрессии и тревожности (педагог-психолог образовательной организации);

- информирование родителей об организациях, где родители могут получать более широкий спектр профилактических программ по работе с детьми

https://rg.ru/2013/10/16/obrprogrammy-dok.html (дата обращения: 12.09.2021). Текст: электронный. 
Э. Л. Ванданова. Благополучие детей: стратегия и практика сопровождения семей с детьми, имеющими психолого-педагогические проблемы

и подростками, имеющими психолого-педагогические проблемы (педагогпсихолог и/или социальный педагог образовательной организации);

- проведение родительских собраний по теме профилактики агрессивного поведения детей и подростков (классный руководитель, педагог-психолог образовательной организации).

Заключение. Для реализации методической помощи органам управления образованием субъектов Российской Федерации могут быть предложены методические рекомендации по организации психолого-педагогического сопровождения детей и подростков, имеющих проблемы. Сопровождение семей, имеющих детей и подростков, определяется не только организацией работы с детьми, но и сопровождением детско-родительских отношений. При организации психолого-педагогического сопровождения в образовательных организациях семей с детьми, имеющими психолого-педагогические проблемы, следует особо обращать внимание на механизмы сопровождения, содержащиеся во ФГОС:

- реализация вариативности психолого-педагогического сопровождения участников образовательного процесса ${ }^{1}$;

- реализация (индивидуальных образовательных маршрутов) адаптированной образовательной программы ${ }^{2}$;

- преемственности при переходе от дошкольного уровня образования к начальному и от начального к среднему.

Организация психолого-педагогического сопровождения позволяет улучшать образовательную среду для всех участников образовательного процесса, что, в свою очередь, способствует условиям повышения благополучия детей.

\section{Литература}

1. Бонивелл И. Ключи к благополучию: что может позитивная психология. Москва: Время, 2009. 192 с. Текст: непосредственный.

2. Леонтьев Д. А. Позитивная психология - повестка дня нового столетия // Психология. Журнал ВШЭ. 2012. № 4. URL: https://cyberleninka.ru/article/n/pozitivnayapsihologiya-povestka-dnya-novogo-stoletiya (дата обращения: 02.03.2021). Текст: электронный.

${ }^{1}$ О сопровождении образования обучающихся с ОВ3 и инвалидностью: письмо Минпросвещения России от 20.02.2019 г. № ТС-551/07 (разъяснения о должностях «тьютор» и «ассистент (помощник)»). URL: https://rulaws.ru/acts/Pismo-MinprosvescheniyaRossii-ot-20.02.2019-N-TS-551_07 (дата обращения: 20.02.2021). Текст: электронный;

О направлении информации: письмо Минпросвещения России от 16.05.2019 г. № TC-1192/03 (по вопросу обучения в группах компенсирующей и комбинированной направленности детей разных категорий). URL: http://www.garant.ru/ products/ipo/prime/doc/72159890/?prime (дата обращения: 20.02.2021). Текст: электронный;

${ }^{2} \mathrm{O}$ направлении информации: письмо Минпросвещения России от 16.05.2019 г. № TC-1192/03 (по вопросу обучения в группах компенсирующей и комбинированной направленности детей разных категорий). URL: http://www.garant.ru/products/ ipo/prime/doc/72159890/?prime (дата обращения: 20.02.2021). Текст: электронный. 
3. Леонтьев Д. А., Сучков Д. Д. Постановка и достижение целей как фактор психологического благополучия // Психологические исследования. 2015. Т. 8, № 44. С. 1. URL: http://psystudy.ru (дата обращения: 20.02.2021). Текст: электронный.

4. Чиксентмихайи М. Поток: психология оптимального переживания. Москва: Смысл; Альпина нон-фикшн, 2011. 464 с. Текст: непосредственный.

5. Casas F., González M., Navarro D. (2014) Social Psychology and Child Well-Being / A. Ben-Arieh, F. Casas, I. Frønes, J. Korbin (eds) // Handbook of Child Well-Being. Springer, Dordrecht. URL: https://doi.org/10.1007/978-90-481-9063-8_187 (дата обращения: 20.02.2021).

6. Fredrickson B. Positivity. New York: Crown, 2009. URL: https://doi.org/10.14515/monitoring. 2020.1.06 (дата обращения: 20.02.2021). Текст: электронный.

7. Nielsen H. B., Thorne B. (2014) Children, Gender, and Issues of Well-Being / A. Ben-Arieh, F. Casas, I. Frønes, J. Korbin (eds) // Handbook of Child Well-Being. Springer, Dordrecht. URL: https://doi.org/10.1007/978-90-481-9063-8_4 (дата обрашения: 20.02.2021).

8. Weisner T. S. (2014) Culture, Context, and Child Well-Being // A. Ben-Arieh, F. Casas, I. Frønes, J. Korbin (eds) Handbook of Child Well-Being. Springer, Dordrecht. URL: https://doi.org/10.1007/978-90-481-9063-8_3 (дата обращения: 20.02.2021).

Статья поступила в редакцию 05.06.2021; одобрена после рецензирования 05.07.2021; принята к публикации 29.11.2021.

\title{
C CHILD WELFARE: STRATEGY AND PRACTICE OF SUPPORTING FAMILIES WITH CHILDREN WITH SPECIAL EDUCATIONAL NEEDS
}

\author{
Elvira L. Vandanova \\ Cand. Sci. (Psychology), A/Prof., \\ Russian Presidential Academy of National Economy and Public Administration \\ 82 Vernadskogo St., Moscow 119571, Russia \\ vandanova-el@ranepa.ru
}

Abstract. The article analyzes the issues of welfare of children with special educational needs, and support of their families in educational institutions. Protection of child rights and psychological safety of children and adults is priority Russian state police in light of the worsening demographic situation, the risks of involving young people in criminal and other destructive activities. In the article we analyzed a number of studies on psychological well-being in children and adolescents in modern educational space, this article focuses on the issues of family and child welfare, ecological approach to welfare of children, exercise of children's rights. We also considered the Russian Federal State Educational Standards (hereinafter FSES) of the second and third generation, identified the conditions for the exercise of the children's right to welfare in accordance with the Russian Law on Education and FSES. One of such conditions is the organization of psychological and pedagogical assistance for all participants of the educational process. The article presents the methodological recommendations for representatives of educational authorities of the constituent entities of the Russian Federation on organization of psychological and pedagogical assistance for families with children and adolescents with special educational needs.

Keywords: child welfare, family, socialization, state education policy, special educational needs of children. 
Э. Л. Ванданова. Благополучие детей: стратегия и практика сопровождения семей с детьми, имеющими психолого-педагогические проблемы

Acknowledgements. The study was performed within the framework of academic research work of Federal Institute for the Development of Education of the Russian Presidential Academy of National Economy and Public Administration.

\section{For citation}

Vandanova E. L. Child Welfare: Strategy and Practice of Supporting Families with Children with Special Educational Needs. Education. Person. Society. 2021; 2: 28-39 (In Russ.).

The article was submitted 05.06.2021; approved after reviewing 05.07.2021; accepted for publication 29.11.2021. 